\title{
Gating of Sensory Input at Subcortical and Cortical Levels during Grasping in Humans
}

\author{
Yuming Lei, Recep A. Ozdemir, and Monica A. Perez \\ University of Miami, Department of Neurological Surgery, The Miami Project to Cure Paralysis, Miami, Florida 33136, and Bruce W. Carter Department of \\ Veterans Affairs Medical Center, Miami, Florida 33125
}

\begin{abstract}
Afferent input from the periphery to the cortex contributes to the control of grasping. How sensory input is gated along the ascending sensory pathway and its functional role during gross and fine grasping in humans remain largely unknown. To address this question, we assessed somatosensory-evoked potential components reflecting activation at subcortical and cortical levels and psychophysical tests at rest, during index finger abduction, precision, and power grip. We found that sensory gating at subcortical level and in the primary somatosensory cortex (S1), as well as intracortical inhibition in the S1, increased during power grip compared with the other tasks. To probe the functional relevance of gating in the $S 1$, we examined somatosensory temporal discrimination threshold by measuring the shortest time interval to perceive a pair of electrical stimuli. Somatosensory temporal discrimination threshold increased during power grip, and higher threshold was associated with increased intracortical inhibition in the $\mathrm{S} 1$. These novel findings indicate that humans gate sensory input at subcortical level and in the S1 largely during gross compared with fine grasping. Inhibitory processes in the S1 may increase discrimination threshold to allow better performance during power grip.
\end{abstract}

Key words: discrimination threshold; grasping; power grip; sensory gating; sensory information; somatosensory cortex

\section{Significance Statement}

Most of our daily life actions involve grasping. Here, we demonstrate that gating of afferent input increases at subcortical level and in the primary somatosensory cortex (S1) during gross compared with fine grasping in intact humans. The precise timing of sensory information is critical for human perception and behavior. Notably, we found that the ability to perceive a pair of electrical stimuli, as measured by the somatosensory temporal discrimination threshold, increased during power grip compared with the other tasks. We propose that reduced afferent input to the $\mathrm{S} 1$ during gross grasping behaviors diminishes temporal discrimination of sensory processes related, at least in part, to increased inhibitory processes within the $S 1$.

\section{Introduction}

Somatosensory information plays a critical role in the control of grasping behaviors (for review, see Kaas, 1993; Johansson and Flanagan, 2009). For example, lesion studies in monkeys showed significant deficits in the control of finger movements during precision grip after temporary inactivation of area $3 \mathrm{~b}$, a region that is involved in processing of cutaneous and proprioceptive

Received Feb. 27, 2018; revised May 9, 2018; accepted June 22, 2018.

Author contributions:Y.L., R.A.O., and M.A.P. wrote the first draft of the paper; Y.L., R.A.O., and M.A.P. edited the paper; Y.L., R.A.O., and M.A.P. designed research; Y.L., R.A.O., and M.A.P. performed research; Y.L., R.A.O., and M.A.P. contributed unpublished reagents/analytic tools; Y.L., R.A.O., and M.A.P. analyzed data; Y.L., R.A.O., and M.A.P. wrote the paper.

This work was supported by National Institute of Neurological Disorders and Stroke Grants R01NS076589-01 and R01NS090622-01 to M.A.P., Department of Veterans Affairs Grants I01RX000815 and I01RX001807 to M.A.P., and Craig H. Neilsen Foundation Grant 454590 to Y.L.

The authors declare no competing financial interests.

Correspondence should be addressed to Dr. Monica A. Perez, Department of Neurological Surgery, The Miami Project to Cure Paralysis, University of Miami, Miami, FL 33136. E-mail: perezmo@miami.edu.

DOI:10.1523/JNEUROSCI.0545-18.2018

Copyright $\odot 2018$ the authors $\quad 0270-6474 / 18 / 387237-11 \$ 15.00 / 0$ input (Hikosaka et al., 1985; Brochier et al., 1999). In agreement, patients with partial (Blennerhassett et al., 2007; Enders and Seo, 2017) and complete (Rothwell et al., 1982) somatosensory loss showed an impaired ability for surface discrimination and grip force control during grasping. Gating of sensory input occurs at cortical and subcortical levels in the ascending sensory pathway in a task-dependent manner (Ghez and Pisa, 1972; Coulter et al., 1974; Tsumoto et al., 1975; Chapman et al., 1988; Hantman and Jessell, 2010; Seki and Fetz, 2012). Despite all this evidence, the mechanisms contributing to somatosensory gating during fine and gross grasping in humans remain unknown.

Somatosensory-evoked potentials (SSEPs) are commonly used to assess transmission at different levels of the ascending sensory pathway. SSEP components, such as the P14, likely reflect the arrival of medial lemniscal signals to the thalamus (Desmedt and Cheron, 1981; Lee and Seyal, 1998), whereas the N20 and P25 likely reflect activation of cortical area 3b (Allison et al., 1991; Forss et al., 1994; Huttunen et al., 2006) and area 1 (Jones et al., 1978; Allison et al., 1991; Ishikawa et al., 2007), respectively. 
SSEPs are attenuated during voluntary activity compared with rest, reflecting gating of afferent input to filter irrelevant signals during a motor behavior, and the magnitude of sensory gating depends on the nature of the motor task (Starr and Cohen, 1985; Borich et al., 2015; Sugawara et al., 2016; Lei and Perez, 2017). Here, we used SSEPs to assess contributions from cortical and subcortical regions to sensory gating during fine and gross grasping in humans.

Neuroimaging studies showed differential activation in the primary somatosensory cortex (S1) during both fine and gross grasping (Ehrsson et al., 2000) and during grasping tasks involving activation of different number of digits (Begliomini et al., 2007; Fabbri et al., 2016). The longlatency component of the cutaneous reflex, which likely reflects activity in the S1 (Jenner and Stephens, 1982), is reduced during power grip compared with more isolated finger voluntary contractions (Datta et al., 1989). Moreover, corticospinal excitability is reduced during power grip compared with more fine hand motor tasks, and subcortical pathways contribute, at least in part, to this effect (Tazoe and Perez, 2017). We hypothesized a more pronounced gating of sensory input at the $\mathrm{S} 1$ and at subcortical levels during power grip compared with precision grip. Electrophysiological (Conte et al., 2012) and neuroimaging (Pastor et al., 2004) studies showed that the $\mathrm{S} 1$ contributes to somatosensory temporal discrimination threshold (STDT). Behavioral studies showed that STDT changes in a task-dependent manner, and its modulation occurs via sensory gating processes in the S1 (Conte et al., 2016). Therefore, to examine the functional role of somatosensory gating, we tested the STDT, measured by the shortest time interval to perceive a pair of electrical stimuli, during power and precision grip.

\section{Materials and Methods}

Subjects. Twenty-two right-handed healthy volunteers (31.2 \pm 10.1 years old, 7 females) participated in the study. The study was performed in accordance with the Declaration of Helsinki. All subjects gave informed consent to the experimental procedures, which were approved by the local ethics committee at the University of Miami. A total of 18 subjects participated in all main experiments and 4 additional subjects were added to the control experiments since some of the original subjects could not return for more testing.

$E M G$ recordings. EMG was recorded from the first dorsal interosseous (FDI) muscle through surface electrodes (Ag-AgCl; $10 \mathrm{~mm}$ diameter) secured to the skin over the belly of the muscle. EMG signals were amplified and filtered (bandwidth $30-2000 \mathrm{~Hz}$ ) with a bioamplifier (Neurolog System, Digitimer) and then converted to digital data with a sampling rate of $5 \mathrm{kHz}$ with an A/D converter (CED Micro 1401, Cambridge Electronic Design) and stored on a computer for off-line analysis.
Experimental paradigm. Subjects were seated in a custom chair with both arms flexed at the elbow by $90^{\circ}$. Testing was completed when subjects performed index finger abduction, precision, and power grip (Fig. $1 A$ ) in a randomized order. During index finger abduction, subjects were instructed to press with their index finger against a custom lever in the abduction direction with the forearm pronated and the wrist restrained by straps. During precision grip, subjects were instructed to grasp a small cylinder (diameter, $6 \mathrm{~mm}$; length, $31 \mathrm{~mm}$; weight, $1.36 \mathrm{~g}$ ) (Bunday et al., 2014) between the thumb and index finger while the forearm was maintained in the neutral position and the wrist was restrained by straps. During power grip, subjects were instructed to grasp the same small cylinder within the hand while all fingers were flexed at the metacarpophalangeal and proximal interphalangeal joints, with the forearm maintained in the neutral position and the wrist restrained by straps (Tazoe and Perez, 2017). The cylinder was maintained in vertical position during precision and power grip. During testing, subjects were instructed to maintain $5 \%$ and $30 \%$ of maximal voluntary contraction (MVC; Fig. $1 B$ ) in the FDI muscle during index finger abduction, precision, and power grip. At the beginning of the experiment, subjects performed two or three brief MVCs for 3-5 s into index finger abduction, separated by $60 \mathrm{~s}$ of rest. EMG activity from the FDI muscle was displayed continuously on an oscilloscope, and verbal feedback was provided to the subjects to ensure 
A



C

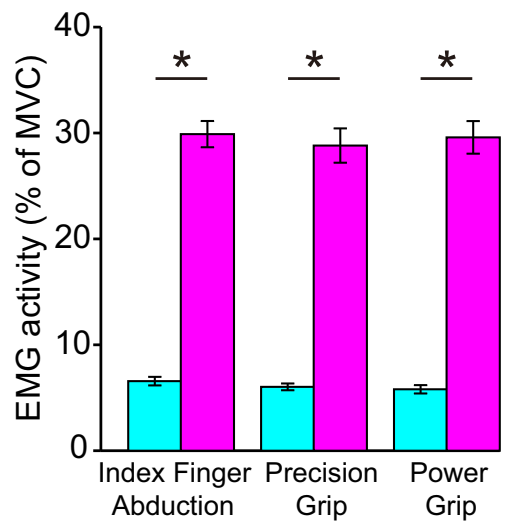

D



Figure 2. EMG activity and M-wave. $\boldsymbol{A}, \boldsymbol{B}$, Rectified EMG activity $(\boldsymbol{A})$ and M-wave $(\boldsymbol{B})$ measured in the right FDI muscle in a representative subject when the right hand performed $5 \%$ (teal) and $30 \%$ (pink) of MVC. Colored lines indicate the smoothed rectified EMG when the right hand performed $5 \%$ (teal) and 30\% (pink) of MVC. C, D, Group data $(n=18)$ showing mean rectified EMG activity (expressed as percentage of MVC) (C) and mean M-wave $(\boldsymbol{D})$ during index finger abduction, precision, and power grip. Error bars indicate $S E$. ${ }^{*} p<0.05$, comparison between $5 \%$ and $30 \%$ of MVC.

that physiological measurements were acquired at similar levels of background EMG activity during 5\% of MVC (index finger abduction = $6.3 \pm 1.9 \%$, precision grip $=5.9 \pm 1.3 \%$, power grip $=5.6 \pm 1.6 \%$; $\left.F_{(1.3,20.6)}=1.7, p=0.2\right)$ and $30 \%$ of MVC (index finger abduction $=$ $27.5 \pm 3.6 \%$, precision grip $=27.0 \pm 6.3 \%$, power grip $=27.2 \pm 4.9 \%$; $F_{(2,32)}=0.1, p=0.9$; Fig. $\left.2 A, C\right)$. A total of $6.5 \pm 2.3 \%$ trials in which mean rectified EMG activity was \pm 2 SD of the mean EMG, measured 100 $\mathrm{ms}$ before the stimulus artifact, were excluded from the analysis (Bunday et al., 2014). We examined motor output steadiness by measuring the coefficient of variation (CV) of the rectified EMG (SD/mean EMG) signals from the FDI muscles during all tasks (Perez and Rothwell, 2015). Physiological measurements included SSEPs (P14/N20, N20/P25, and P25/N33 SSEP components) and paired-pulse SSEP suppression within the S1. STDT was measured to analyze temporal process of sensory inputs in the $\mathrm{S} 1$ as described below.

SSEPs. We recorded SSEPs from the left $\mathrm{S} 1$ following electrical stimulation of the right ulnar nerve at the wrist $(300$ pulses at $5 \mathrm{~Hz}, 0.1 \mathrm{~ms}$ pulse duration), with pairs of adhesive $\mathrm{Ag}-\mathrm{AgCl}$ electrodes positioned $5 \mathrm{~cm}$ lateral, $5 \mathrm{~cm}$ anterior (frontal component), and $2 \mathrm{~cm}$ posterior (parietal component) to the vertex. These locations correspond to regions anterior and posterior of the $\mathrm{C} 3$ area in the 10-20 system (Fig. 1C) (Lei and Perez, 2017). The ground electrode was located on the forehead. The peak-to-peak amplitude of SSEP components (P14/N20, N20/P25, and P25/N33; Fig. 1D) was tested while the FDI was at rest or maintain $5 \%$ and $30 \%$ of MVC during index finger abduction, precision, and power grip (Fig. $2 \mathrm{~A}, \mathrm{C}$ ). The $\mathrm{P} 14$ component could be reliably identified in 10 of 18 subjects in all tasks, consistent with previous results (Ragert et al.,
2011). Therefore, the data were analyzed for all SSEP components $(n=10)$ and for the N20/ P25 and P25/N33 separately $(n=18)$. When the P14 was present, its amplitude was measured from the P14 to the N20 peak (P14/N20), the N20 was measured from the N20 to the P25 peak (N20/P25), and the P25 was measured from the P25 to the N33 peak (P25/N33). When the P14 was not present, the N20 was measured from the baseline to the P25 peak (N20/P25) and the P25 was measured from the $\mathrm{P} 25$ to the N33 peak (P25/N33). Baseline was defined as the mean amplitude $100 \mathrm{~ms}$ before the stimulus artifact and onset latency as values $2 \mathrm{SD}$ above the mean baseline. At rest, the P14/ $\mathrm{N} 20(1.1 \pm 0.5 \mu \mathrm{V})$ was smaller compared with the N20/P25 $(2.9 \pm 1.5 \mu \mathrm{V}, p<0.001)$ and $\mathrm{P} 25 / \mathrm{N} 33(2.5 \pm 1.1 \mu \mathrm{V}, p<0.001 ; n=10)$. No difference was found between the amplitude of the N20/P25 $(3.1 \pm 1.4 \mu \mathrm{V})$ and P25/N33 $(2.9 \pm 1.1 \mu \mathrm{V}, p=0.4 ; n=18)$. To assess possible spillover effects from a previous component, the N20/P25 and P25/N33 were also measured from baseline to the P25 and N33 peak, respectively (Cohen and Starr, 1987). Similarly, no differences were found between the amplitude of the N20/P25 $(1.6 \pm 1.2 \mu \mathrm{V})$ and $\mathrm{P} 25 / \mathrm{N} 33(1.3 \pm 1.7 \mu \mathrm{V}, p=0.3)$ measured from baseline to the P25 and N33 peak ( $n=$ 10 ). Signals were amplified (gain $50 \mathrm{~K}$, bandwidth $3 \mathrm{~Hz}$ to $2 \mathrm{kHz}$ ), and the stimuli were delivered at an intensity of $\sim 10 \%$ of the maximal motor response (M-max) across tasks during $5 \%$ of MVC (index finger abduction = $11.3 \pm 2.0 \%$ of $\mathrm{M}$-max, precision grip $=$ $12.0 \pm 3.1 \%$ of M-max, power grip $=11.7 \pm$ $2.9 \%$ of $\left.M-\max ; F_{(2,32)}=1.3, p=0.3\right)$ and $30 \%$ of MVC (index finger abduction $=11.4 \pm$ $2.1 \%$ of M-max, precision grip $=11.5 \pm 2.3 \%$ of M-max, power grip $=11.7 \pm 2.5 \%$ of $\mathrm{M}$ $\max ; F_{(2,32)}=0.1, p=0.9$; Fig. $\left.2 B, D\right)$. Because we found that sensory gating increased during power grip compared with the other tasks, we performed two control experiments to assess the contribution of different fingers to our effects. First, we examined the effect of the number of digits used during a precision grip on SSEP measurements by testing SSEPs during a precision grip using the index finger and thumb and a precision grip with all five digits $(n=8)$. Second, we examined the contribution of afferent input from different fingers during precision grip by testing SSEPs during a precision grip using index finger and thumb, middle finger and thumb, ring finger and thumb, and little finger and thumb $(n=8)$.

Paired-pulse SSEP suppression. Paired-pulse SSEP suppression was measured to make inferences about the contribution of intracortical inhibitory mechanisms on SSEP components (Höffken et al., 2013). Paired-pulse SSEP suppression was measured in the left S1 using a paired-pulse paradigm where repeated paired pulses were applied to the right ulnar nerve at the wrist at an interstimulus interval (ISI) of $40 \mathrm{~ms}$, whereas the FDI maintained $30 \%$ of MVC during index finger abduction, precision grip, and power grip $(n=12)$. The stimulation was given at an intensity needed to elicit a response in the left FDI muscle of $\sim 10 \%$ of the $\mathrm{M}-\mathrm{max}$ across conditions (index finger abduction $=11.2 \pm 2.9 \%$ of $\mathrm{M}$-max, precision grip $=11.9 \pm 2.4 \%$ of $\mathrm{M}$-max, power grip $=12.2 \pm$ $2.8 \%$ of $\mathrm{M}$-max; $\left.F_{(2,32)}=1.3, p=0.3\right)$. Paired-pulse SSEP suppression was calculated as a ratio of the amplitude of the second response (A2) and the amplitude of the first response (A1) measured in each of the SSEP components. Because the amplitude of A1 decreased during power grip compared with index finger abduction and precision grip, paired-pulse SSEP suppression was also tested adjusting the size of Al by asking sub- 


\begin{tabular}{|c|c|c|c|c|c|}
\hline & Rest & Index finger abduction & Precision grip & Power grip & $\overline{p^{b}}$ \\
\hline \multicolumn{6}{|c|}{ SSEP latency in subjects showing all SSEP components $(n=10)$} \\
\hline \multicolumn{6}{|l|}{$5 \%$ of MVC } \\
\hline P14 (ms) & $16.8 \pm 1.3$ & $16.5 \pm 1.1$ & $16.8 \pm 1.2$ & $16.6 \pm 1.4$ & 0.9 \\
\hline N20 (ms) & $20.6 \pm 1.0$ & $20.5 \pm 0.8$ & $20.9 \pm 0.8$ & $20.5 \pm 1.0$ & 0.7 \\
\hline P25 (ms) & $25.2 \pm 3.0$ & $24.7 \pm 2.9$ & $25.1 \pm 1.9$ & $25.7 \pm 2.3$ & 0.8 \\
\hline \multicolumn{6}{|l|}{$30 \%$ of MVC } \\
\hline P14 (ms) & $16.6 \pm 1.3$ & $16.7 \pm 1.6$ & $16.8 \pm 0.8$ & $17.1 \pm 1.3$ & 0.9 \\
\hline $\mathrm{N} 20$ (ms) & $20.1 \pm 1.0$ & $20.0 \pm 0.7$ & $20.3 \pm 0.9$ & $20.7 \pm 1.2$ & 0.4 \\
\hline P25 (ms) & $25.0 \pm 2.6$ & $24.7 \pm 2.5$ & $25.3 \pm 2.9$ & $24.9 \pm 2.8$ & 0.9 \\
\hline \multicolumn{6}{|c|}{ Latency of N20 and P25 in all subjects tested $(n=18)$} \\
\hline \multicolumn{6}{|l|}{$5 \%$ of MVC } \\
\hline $\mathrm{N} 20$ (ms) & $20.6 \pm 1.2$ & $20.4 \pm 1.5$ & $20.5 \pm 1.4$ & $20.7 \pm 1.2$ & 0.8 \\
\hline P25 (ms) & $24.8 \pm 3.0$ & $24.5 \pm 2.8$ & $24.7 \pm 2.2$ & $24.9 \pm 2.7$ & 0.9 \\
\hline \multicolumn{6}{|l|}{$30 \%$ of MVC } \\
\hline $\mathrm{N} 20$ (ms) & $20.3 \pm 1.4$ & $20.3 \pm 1.5$ & $20.3 \pm 1.3$ & $20.5 \pm 1.4$ & 0.9 \\
\hline P25 (ms) & $24.6 \pm 2.6$ & $24.4 \pm 2.7$ & $24.6 \pm 2.6$ & $24.4 \pm 2.8$ & 0.8 \\
\hline
\end{tabular}

${ }^{a}$ Mean SSEP latency for all components ( $\left.n=10\right)$ and for the N20 and P25 separately $(n=18)$.

${ }^{b} p$ values represent ANOVA tests performed across tasks at each force level.

jects to perform $5 \%$ of MVC during power grip. A total of 300 pairedpulses were applied during each task.

STDT. We used a previously established paired-pulse paradigm to test STDT (Conte et al., 2010, 2012) at rest and during 30\% of MVC while performing index finger abduction, precision, and power grip $(n=12)$. The electrical perceptual threshold (EPT) was measured by using constant current square wave electrical pulses $(0.5 \mathrm{~ms}$ pulse width duration, $3 \mathrm{~Hz}$ stimulation frequency, DS7A, Digitimer) through surface electrodes with the anode located $0.5 \mathrm{~cm}$ distally to the cathode. The electrodes were applied on the distal phalanx of the right index finger. The EPT was defined for each subject by delivering series of stimuli that were manually increased in increments of $0.1 \mathrm{~mA}$ up to $10 \mathrm{~mA}$. Subjects were asked to report verbally when the first sensation was felt. The intensity used for STDT was $1.5 \times$ EPT. Each subject was given practice trials to recognize the electrical pulses and familiarize with the task. STDT was assessed by delivering pairs of stimuli starting with ISI of $0 \mathrm{~ms}$ and progressively increasing the ISI steps by $10 \mathrm{~ms}$. Subjects were asked to report verbally whether they perceived a single stimulus or two temporally separate stimuli. The first of three consecutive ISIs at which participants recognized the stimuli as temporally separated was considered STDT. To keep the subject's attention level constant during the test and to minimize the risk of perseverative responses, the STDT testing procedure included "catch" trials consisting of a single stimulus delivered randomly.

Data analysis. Normal distribution was tested by the Shapiro-Wilk's test and homogeneity of variances by the Levene's test of equality and Mauchly's test of sphericity. When normal distribution could not be assumed, data were log transformed. When sphericity could not be assumed, the Greenhouse-Geisser correction statistic was used. Repeated measures ANOVAs were performed to determine the effect of FORCE ( $5 \%$ and $30 \%$ of MVC) and TASK (index finger abduction, precision and power grip) on the CV EMG. The same analysis was used to determine the effect of CONDITION (rest, index finger abduction, precision grip, and power grip) and FORCE on the M-wave, and mean rectified EMG activity and the effect of FORCE, CONDITION and COMPONENT (P14/N20, N20/P25, and P25/N33) on the latency and amplitude of each SSEP component when measured from baseline and from the preceding peak. We also examined the effect FORCE and CONDITION on the latency and amplitude of the N20/P25 and P25/N33 SSEP components. In addition, repeated measures ANOVAs were used to determine the effect of FORCE, TASK, and COMPONENT on the amplitude of each SSEP component and the effect of TASK on paired-pulse SSEP suppression and STDT and the effect of DIGITS (thumb and middle finger, thumb and ring finger, and thumb and little finger) and NUMBER OF DIGITS (precision grip with two and five digits) on the amplitude of each SSEP component as needed. Tukey post hoc analysis was used to test for significant comparisons. Pearson correlation analysis was used as needed corrected for multiple comparisons. Significance was set at $p<0.05$. Group data are presented as mean \pm SD.

\section{Results}

\section{EMG and M-wave}

Figure $2 A, B$ illustrate examples of rectified EMG activity and $\mathrm{M}$-wave measured in the right FDI across force levels in a representative subject. EMG activity increased during increasing levels of voluntary contraction, whereas the $\mathrm{M}$-wave remained similar.

Repeated-measures ANOVA showed an effect of FORCE $\left(F_{(1,17)}=1046.2, p<0.001\right)$, CONDITION $\left(F_{(3,51)}=306.7, p<\right.$ $0.001)$, and in their interaction $\left(F_{(3,51)}=162.0, p<0.001\right)$ on mean rectified EMG activity in the FDI. Post hoc analysis showed that EMG activity increased at $30 \%$ and $5 \%$ of MVC compared with rest during all tasks (index finger abduction: $5 \%$ of $\mathrm{MVC}=$ $6.4 \pm 1.7 \%, p<0.001,30 \%$ of $\mathrm{MVC}=26.8 \pm 3.5 ; p<0.001$; precision grip: $5 \%$ of $\mathrm{MVC}=5.9 \pm 1.3 \%, p<0.001,30 \%$ of $\mathrm{MVC}=27.1 \pm 5.7 ; p<0.001$; power grip: $5 \%$ of $\mathrm{MVC}=5.7 \pm$ $1.7 \%, p<0.001 ; 30 \%$ of $\mathrm{MVC}=25.8 \pm 3.3 ; p<0.001)$. Mean rectified EMG activity was larger at $30 \%$ compared with $5 \%$ of MVC during index finger abduction $(p<0.001)$, precision $(p<$ $0.001)$, and power grip ( $p<0.001$; Fig. $2 C)$. We found no effect of $\operatorname{FORCE}\left(F_{(1,17)}=0.07, p=0.8\right)$, CONDITION $\left(F_{(1.7,28.1)}=\right.$ $0.4, p=0.7)$, and in their interaction $\left(F_{(1.4,24.2)}=1.0, p=0.4\right.$; Fig. $2 D)$ on the $M$-wave amplitude used during testing.

We also found an effect of TASK $\left(F_{(2,34)}=3.8, p=0.03\right)$, but not FORCE $\left(F_{(1,17)}=3.0, p=0.1\right)$, or in their interaction $\left(F_{(2,34)}=0.1, p=0.9\right)$ on the CV of the EMG. The CV decreased during power grip $(0.92 \pm 0.06)$ compared with index finger abduction $(0.96 \pm 0.07, p=0.01)$ and precision grip $(0.95 \pm$ $0.09, p=0.03)$ at $30 \%$ of MVC. The CV increased during power grip $(p=0.04)$, but not index finger abduction $(p=0.2)$ or precision grip $(p=0.2)$, at $30 \%$ of MVC compared with $5 \%$ of MVC.

\section{SSEP latency}

Repeated-measures ANOVA showed an effect of COMPONENT $\left(F_{(2,18)}=117.1, p<0.001\right)$, but not $\operatorname{FORCE}\left(F_{(1,9)}=1.2, p=\right.$ $0.3)$, CONDITION $\left(F_{(3,27)}=2.3, p=0.1\right)$, or in their interaction $\left(F_{(6,54)}=1.4, p=0.2\right)$ on SSEP latency. The latency of the P14 $(p=0.9), \mathrm{N} 20(p=0.4)$, and P25 $(p=0.9)$ was similar across conditions (Table 1). Repeated-measures ANOVA also revealed an effect of COMPONENT $\left(F_{(1,17)}=42.5, p<0.001\right)$, but not 
FORCE $\left(F_{(1,17)}=2.3, p=0.1\right)$, CONDITION $\left(F_{(3,51)}=1.7, p=\right.$ $0.2)$, or in their interaction $\left(F_{(3,51)}=0.4, p=0.8\right)$ on the latency of N20 and P25. No differences were found across conditions for the $\mathrm{N} 20(p=0.9)$ and P25 $(p=0.8$; Table 1$)$.

\section{SSEP amplitude}

Repeated-measures ANOVA showed an effect of COMPONENT $\left(F_{(2,18)}=4.1, p=0.03\right)$, FORCE $\left(F_{(1,9)}=21.2, p<0.001\right)$, CONDITION $\left(F_{(3,27)}=32.9, p<0.001\right)$, but not in their interaction $\left(F_{(6,54)}=1.8, p=0.1\right)$ on SSEP amplitude. The P14/N20 amplitude was reduced at $5 \%$ and $30 \%$ of MVC compared with rest during index finger abduction $(5 \%$ of $\mathrm{MVC}=85.9 \pm 15.9 \%$, $p=0.02 ; 30 \%$ of $\mathrm{MVC}=62.7 \pm 21.0 ; p<0.001)$, precision grip $(5 \%$ of MVC $=84.9 \pm 14.9 \%, p=0.02 ; 30 \%$ of $\mathrm{MVC}=62.3 \pm$ $25.7 ; p=0.001)$, and power grip ( $5 \%$ of MVC $=68.6 \pm 24.7 \%$, $p=0.003 ; 30 \%$ of $\mathrm{MVC}=40.3 \pm 20.7 ; p<0.001)$. The P14/N20 amplitude was reduced largely during $30 \%$ compared with $5 \%$ of MVC during all tasks (index finger abduction, $p=0.006$; precision grip, $p=0.02$; power grip, $p=0.02$; Fig. $3 A$ ). We also found that the N20/P25 and P25/N33 amplitudes were reduced at 5\% and $30 \%$ of MVC compared with rest during index finger abduction (N20/P25: $5 \%$ of MVC $=90.8 \pm 9.1 \%, p=0.01 ; 30 \%$ of $\mathrm{MVC}=75.7 \pm 15.3 ; p<0.001 ; \mathrm{P} 25 / \mathrm{N} 33: 5 \%$ of $\mathrm{MVC}=89.7 \pm$ $10.5 \%, p=0.01 ; 30 \%$ of MVC $=78.0 \pm 16.2 ; p=0.002)$, precision $(\mathrm{N} 20 / \mathrm{P} 25: 5 \%$ of $\mathrm{MVC}=85.5 \pm 13.9 \%, p=0.009 ; 30 \%$ of $\mathrm{MVC}=69.8 \pm 16.7 ; p<0.001 ; \mathrm{P} 25 / \mathrm{N} 33: 5 \%$ of $\mathrm{MVC}=83.3 \pm$ $17.2 \%, p=0.01 ; 30 \%$ of MVC $=76.1 \pm 18.4 ; p=0.002)$, and power (N20/P25: $5 \%$ of MVC $=84.4 \pm 15.1 \%, p=0.01 ; 30 \%$ of $\mathrm{MVC}=57.2 \pm 13.7 ; p<0.001 ;$ Fig. $3 B ; \mathrm{P} 25 / \mathrm{N} 33: 5 \%$ of $\mathrm{MVC}=$ $81.1 \pm 25.4 \%, p=0.04 ; 30 \%$ of $\mathrm{MVC}=76.7 \pm 16.6 ; p=0.002$; Fig. $3 C$ ) grip. However, the N20/P25, but not P25/N33, amplitude was more suppressed at $30 \%$ compared with $5 \%$ of MVC across tasks when the components were analyzed from the previous peak (index finger abduction, N20/P25: $p=0.03 ; \mathrm{P} 25 / \mathrm{N} 33$ : $p=0.08$; precision grip, $\mathrm{N} 20 / \mathrm{P} 25: p=0.002 ; \mathrm{P} 25 / \mathrm{N} 33: p=0.4$; power grip, N20/P25: $p<0.001 ; \mathrm{P} 25 / \mathrm{N} 33: p=0.8)$ and from the baseline (index finger abduction, N20/P25: $p=0.02 ; \mathrm{P} 25 / \mathrm{N} 33$ : $p=0.2$; precision grip, $\mathrm{N} 20 / \mathrm{P} 25: p=0.01 ; \mathrm{P} 25 / \mathrm{N} 33: p=0.1$; power grip, N20/P25: $p=0.005$; P25/N33: $p=0.5$ ). Similar results were found in subjects who showed the N20/P25 and $\mathrm{P} 25 / \mathrm{N} 33$ without the P14 [FORCE $\left(F_{(1,17)}=5.1, p=0.03\right)$, CONDITION $\left(F_{(3,51)}=21.3, p<0.001\right)$, not COMPONENT $\left(F_{(1,17)}=0.3, p=0.6\right)$, but in their interaction $\left(F_{(3,51)}=3.9, p=\right.$ 0.01 ) on the N20/P25 and P25/N33 amplitude] and when the amplitude of the N20/P25 and P25/N33 was analyzed from the baseline [FORCE $\left(F_{(1,17)}=7.2, p=0.01\right)$, CONDITION $\left(F_{(3,51)}=16.7, p<0.001\right)$, not COMPONENT $\left(F_{(1,17)}=0.8, p=\right.$ $0.5)$, but in their interaction $\left(F_{(3,51)}=4.5, p=0.008\right)$ on the N20/P25 and P25/N33 amplitude].

Figure $4 A$ illustrates examples of SSEP traces recorded in a representative subject at rest (black) and during index finger abduction (blue), precision (gray), and power (orange) grip at 5\% of MVC. The amplitude of the P14/N20, but not N20/P25 and $\mathrm{P} 25 / \mathrm{N} 33$, decreased during power grip compared with index finger abduction and precision grip. Repeated-measures ANOVA showed an effect of TASK $\left(F_{(2,18)}=3.7, p=0.04\right)$, but not COMPONENT $\left(F_{(2,18)}=0.9, p=0.4\right)$ or in their interaction $\left(F_{(4,36)}=1.3, p=0.3\right)$ on SSEP amplitude at $5 \%$ of MVC. The $\mathrm{P} 14 / \mathrm{N} 20$ was more suppressed during power grip compared with index finger abduction and precision grip (power grip $=68.6 \pm$ $24.7 \%$; index finger abduction $=85.9 \pm 15.9 \%, p=0.02$; precision grip $=84.9 \pm 14.9 \%, p=0.01$; Fig. $4 C$ ), whereas no differences were observed in the P14/N20 between index finger
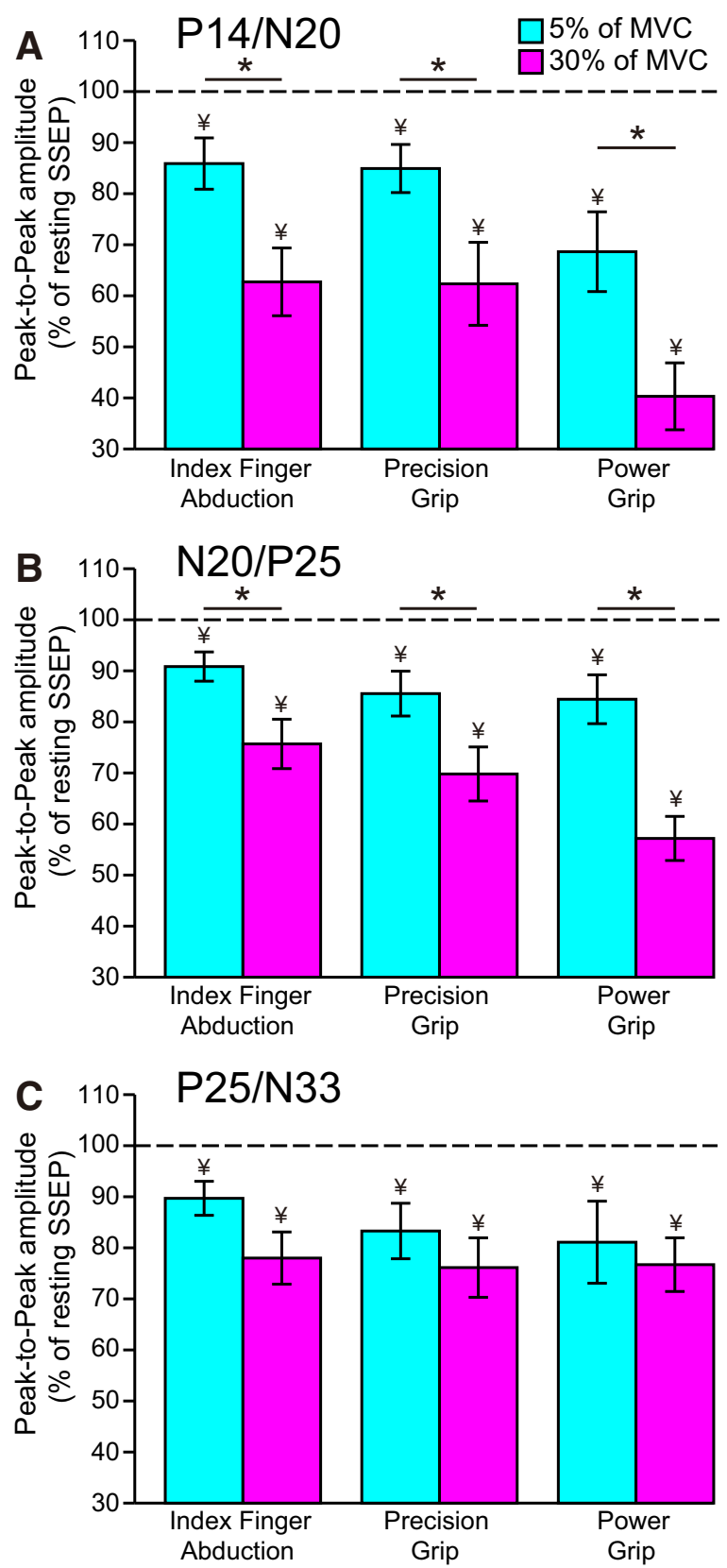

Figure 3. SSEP amplitude. Group data show the amplitude of P14/N20 (A), N20/P25 (B), and P25/N33 (C) SSEP components (expressed as percentage of resting SSEP) during index finger abduction, precision, and power grip at $5 \%$ (teal) and $30 \%$ (pink) of MVC. Horizontal dotted line indicates the amplitude of the SSEP components at rest. Error bars indicate SE. ${ }^{*} p<0.05$, comparison between $5 \%$ and $30 \%$ of MVC. ${ }^{*} p<0.05$, comparison between rest and contraction.

abduction and precision grip ( $p=0.7)$. No differences were also found in the N20/P25 ( $p=0.5)$ and P25/N33 ( $p=0.6)$ amplitude across tasks. Similar results were found in subjects who showed the N20/P25 and P25/N33 without the P14/N20 [TASK $\left.\left(F_{(2,34)}=1.9, p=0.2\right)\right]$.

At $30 \%$ of MVC, the amplitude of the P14/N20 and N20/P25, but not $\mathrm{P} 25 / \mathrm{N} 33$, was reduced during power grip compared with index finger abduction and precision grip (Fig. $4 B$ ). Repeatedmeasures ANOVA showed an effect of TASK $\left(F_{(2,18)}=4.0, p=\right.$ $0.03)$, COMPONENT $\left(F_{(2,18)}=6.4, p=0.008\right)$, and in their interaction $\left(F_{(4,36)}=2.9, p=0.03\right)$ on SSEP amplitude at $30 \%$ of 

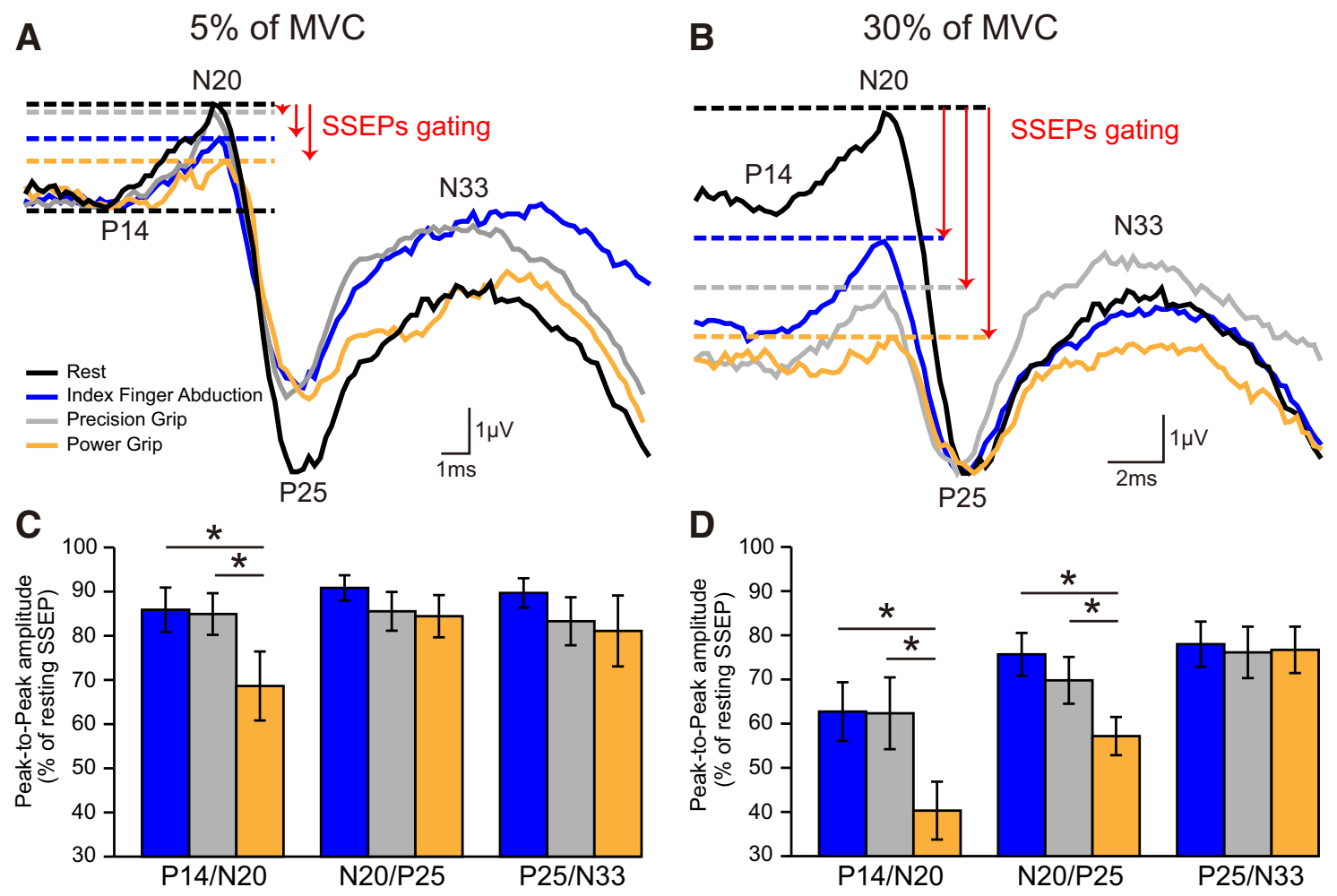

Figure 4. SSEPs during $5 \%$ and $30 \%$ of MVC. Raw SSEP traces recorded from the $\mathrm{S} 1$ in a representative subject when the right FDI was at rest (black) or performed index finger abduction (blue) , precision (gray), and power grip (orange) at $5 \%(\boldsymbol{A})$ and $30 \%(\boldsymbol{B})$ of MVC. Each waveform represents the average of 300 SSEPs. Group data show the amplitude of all SSEP components (expressed as percentage of resting SSEPs) during index finger abduction (blue), precision (gray), and power grip (orange) at $5 \%$ (C) and $30 \%$ (D) of MVC. Error bars indicate SE. ${ }^{*} p<0.05$, comparison between motor tasks.

MVC. The amplitude of the P14/N20 (power grip $=40.3 \pm$ $20.7 \%$; index finger abduction $=62.7 \pm 21.0 \%, p=0.004$; precision grip $=62.3 \pm 25.7 \%, p=0.02$ ) and the $\mathrm{N} 20 / \mathrm{P} 25$ (power grip $=57.2 \pm 13.7 \%$; index finger abduction $=75.7 \pm 15.3 \%$, $p<0.001$; precision grip $=69.8 \pm 16.7 \%, p=0.03$ ), but not $\mathrm{P} 25 / \mathrm{N} 33$ (power grip $=76.7 \pm 16.6 \%$; index finger abduction $=$ $78.0 \pm 16.2 \%, p=0.8$; precision grip $=76.1 \pm 18.4 \%, p=0.9)$ were more attenuated during power grip compared with index finger abduction and precision grip amplitude (Fig. 4D). No differences were found in the amplitude of the P14/N20 $(p=0.9)$, $\mathrm{N} 20 / \mathrm{P} 25(p=0.4)$, and P25/N33 $(p=0.7)$ between index finger abduction and precision grip. The same results were found in subjects who showed the N20/P25 and P25/N33 without the P14/ $\mathrm{N} 20 \operatorname{TASK}\left(F_{(2,34)}=3.8, p=0.03\right), \operatorname{COMPONENT}\left(F_{(1,17)}=\right.$ $4.6, p=0.04)$, and in their interaction $\left(F_{(2,34)}=3.6, p=0.03\right)$ on the N20/P25 and P25/N33 amplitude at 30\% of MVC]. In additional experiments, we found no effect of DIGITS (index finger and thumb, middle finger and thumb, ring finger and thumb, or little finger and thumb, $F_{(3,21)}=0.5, p=0.7$; Fig. $\left.5 A, C\right)$ and NUMBER OF DIGITS (precision grip with two or five digits, $F_{(1,7)}=0.4, p=0.6$; Fig. $\left.5 B, D\right)$ on SSEP amplitude.

\section{Paired-pulse SSEP suppression}

Figure $6 A$ illustrates raw data showing paired-pulse SSEP suppression of the N20/P25 during index finger abduction (blue), precision grip (gray), and power grip (orange) at $30 \%$ of MVC in a representative subject. Paired-pulse suppression of the N20/ P25 was more pronounced during power grip compared with index finger abduction and precision grip.

Repeated-measures ANOVA showed an effect of TASK $\left(F_{(2,22)}=5.1, p=0.01\right)$ on paired-pulse SSEPs within the S1. We found that the A2/A1 ratio decreased during power grip compared with index finger abduction and precision grip for the $\mathrm{N} 20 / \mathrm{P} 25$ (power grip $=65.4 \pm 16.6 \%$; index finger abduction $=$ $77.8 \pm 18.9 \%, p=0.02$; precision grip $=76.3 \pm 18.5 \%, p=$ 0.002 ; Fig. $6 B$ ). No differences were found in the A2/A1 ratio $(p=0.7)$ between index finger abduction and precision grip. Paired-pulse SSEP suppression of the other SSEP components remained similar during index finger abduction, precision, and power grip (P14/N25: $p=0.5 ; \mathrm{P} 25 / \mathrm{N} 33: p=0.6)$. The majority of subjects showed higher paired-pulse SSEP suppression for the N20/P25 during power grip compared with index finger abduction ( 9 of 12 subjects) and precision grip (10 of 12 subjects; Fig. $6 C$ ). Because A1 size decreased during power grip compared with index finger abduction and precision grip, we also tested pairedpulse SSEP suppression by adjusting the size of A1 (see Materials and Methods). Similar to our previous results, we found that the $\mathrm{A} 2 / \mathrm{A} 1$ ratio decreased during power grip compared with index finger abduction $(p=0.02)$ and precision grip $(p=0.02)$ for the N20/P25.

\section{STDT and correlation analysis}

Repeated-measures ANOVA showed an effect of TASK on STDT $\left(F_{(2,22)}=19.8, p<0.001\right.$; Fig. $\left.7 A\right)$. STDT was higher during power grip (142 $\pm 50 \mathrm{~ms}$ ) compared with index finger abduction $(100 \pm 34 \mathrm{~ms}, p<0.001)$ and precision grip (105 $\pm 39 \mathrm{~ms}, p<$ $0.001)$, whereas no differences were found between index finger abduction and precision grip $(p=0.3)$. The majority of subjects showed higher STDT during power grip compared with index finger abduction (11 of 12 subjects) and precision grip (10 of 12 subjects; Fig. 7B). A correlation was found between STDP and paired-pulse SSEP suppression during power grip $(r=0.69, p=$ 
A

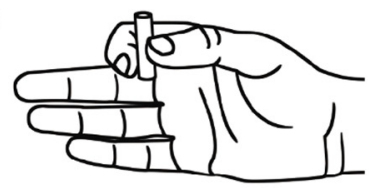

Index Finger and Thumb

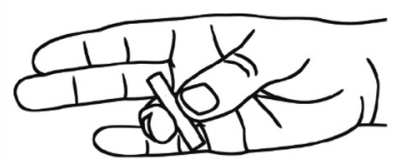

Ring Finger and Thumb

B

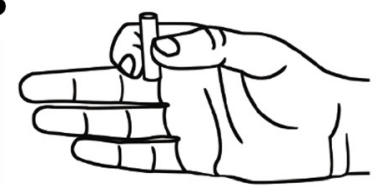

Index Finger and Thumb

C

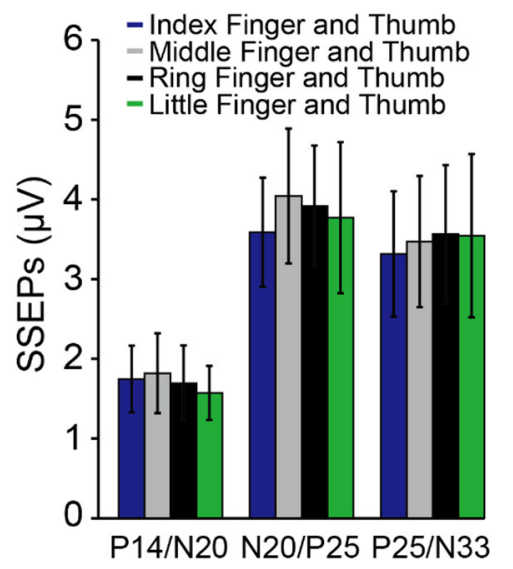

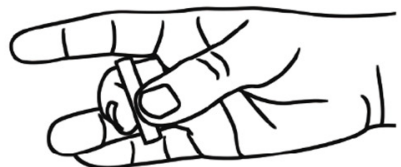

Middle Finger and Thumb

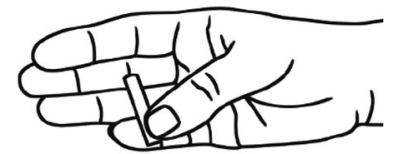

Little Finger and Thumb

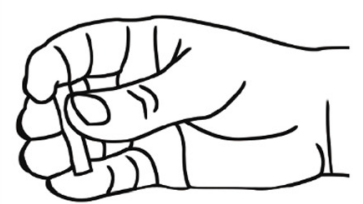

All Five Digits

D

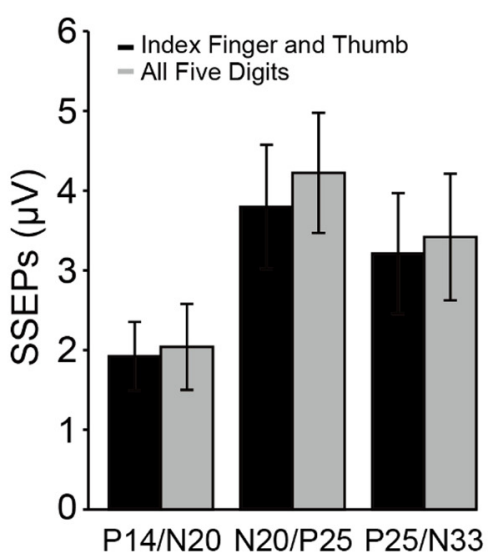

Figure 5. SSEPs during control experiments. SSEPs were tested during a precision grip using index finger and thumb, middle finger and thumb, ring finger and thumb, and little finger and thumb $(\boldsymbol{A})$ and during a precision grip using the index finger and thumb and a precision grip with all five digits $(\boldsymbol{B})$ at $30 \%$ of MVC. Group data $(n=8)$ show the amplitude of all SSEP components (P14/N20, N20/P25, and P25/N33 in microvolts) during a precision grip using index finger and thumb (blue bars), middle finger and thumb (gray bars), ring finger and thumb (black bars), and little finger and thumb (green bars; $\boldsymbol{C}$ ) and during a precision grip using the index finger and thumb (black bars) and a precision grip with all five digits (gray bars; $\boldsymbol{D}$ ). Error bars indicate SE.

0.01; Fig. 7C). Here individuals with higher STDT were those with more pronounced intracortical inhibition of the N20/P25 in the $\mathrm{S} 1$.

\section{Discussion}

We provide evidence that humans gate sensory input at subcortical level and in the S1 more pronouncedly during gross compared with fine grasping. We found that the amplitude of the P14/N20 and N20/P25, SSEP components reflecting contributions from subcortical pathways and the S1, respectively, decreases during power grip compared with the other tasks and rest. Intracortical inhibition in the $\mathrm{S} 1$ reduced the amplitude of the N20/P25 SSEP component during power grip consistent with a cortical origin for this effect. We also found that STDT, reflecting the ability to perceive a pair of electrical stimuli, increased during power grip and higher threshold was associated with increased intracortical inhibition in the S1. Thus, we hypothesize that power grip increases inhibitory processes in the S1 diminishing the ability to discriminate sensory signals during the task.

\section{Mechanisms of sensory gating during grasping}

Somatosensory information is filtered ("gated") at different levels of the ascending sensory pathway during voluntary movement (Ghez and Pisa, 1972; Coulter et al., 1974; Tsumoto et al., 1975; Chapman et al., 1988; Hantman and Jessell, 2010; Seki and Fetz, 2012) and plays a critical role in the control of grasping (Kaas, 1993; Johansson and Flanagan, 2009). Here, we examined, for the first time, the contribution of cortical and subcortical sites to sensory gating during gross and fine grasping in intact humans. We found that gating of the P14/N20 and N20/ P25 SSEP components increased during power grip compared with the other tasks. This agrees with previous findings showing that the magnitude of sensory gating changes according to the nature and characteristics of the motor task (Starr and Cohen, 1985; Borich et al., 2015; Sugawara et al., 2016; Lei and Perez, 2017). The P14/N20 likely reflects the arrival of medial lemniscal signals to the thalamus (Desmedt and Cheron, 1981; Lee and Seyal, 1998), whereas the N20/P25 likely reflects activation of cortical area $3 \mathrm{~b}$ (Allison et al., 1991; Forss et al., 1994; Huttunen et al., 2006). The N20/P25 might be generated by EPSPs in the apical dendrites of somatosensory pyramidal neurons, which are caused by excitatory input from the thalamus (Hashimoto et al., 1996). Power grip could presumably reduce inputs to the thalamus and the S1. Animals (Riddle et al., 2009) and human (Baker and Perez, 2017; Dean and Baker, 2017; Tazoe and Perez, 2017) studies showed that subcortical networks, such as the reticulospinal pathway, contribute to the control of gross grasping behaviors. The ascending reticular system located in the midbrain projects to thalamic neurons (Paré et al., 1988; Steriade et al., 1988) and transmission at the dorsal column nuclei as evidenced by gross lemniscal response is attenuated by reticular stimulation (Dawson, 1958). Therefore, flow of sensory input to the thalamus and thalamocortical networks to the $\mathrm{S} 1$ could be diminished during power grip. The reticular nuclei can process sensory input from the periphery without the need to pass through the cortex (Leiras et al., 2010). Thus, another possibility is that sensory gating at the cortex is greater for power grip, as integration of sensory feedback, is managed at a subcortical level. We also found that paired-pulse SSEP suppression in the S1 reduced the amplitude of the N20/P25, but not other SSEP components, during power grip compared with the 

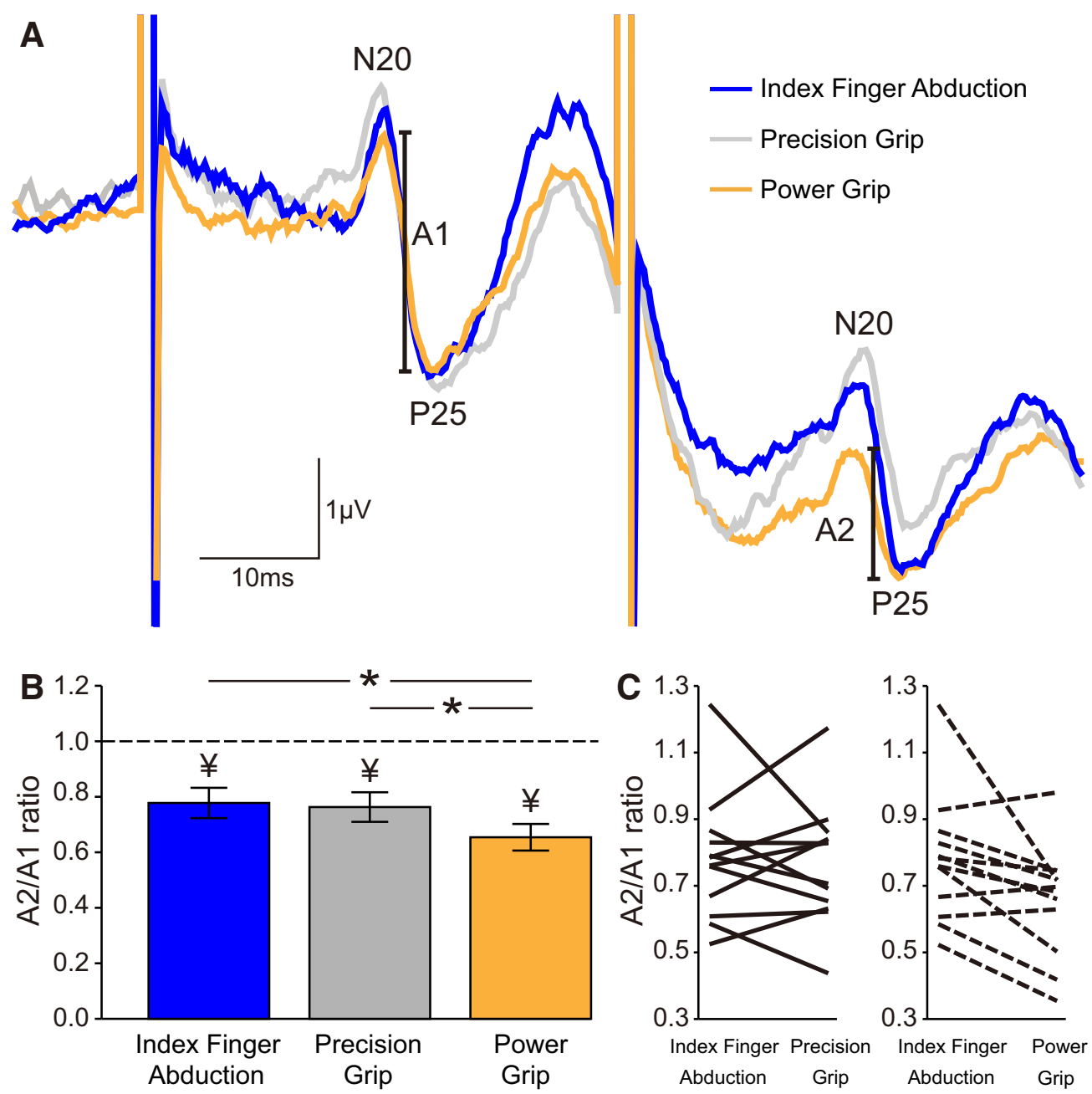

Figure 6. Paired-pulse SSEP suppression within the S1. A, Raw SSEP traces showing paired-pulse SSEP suppression of the N20/P25 in the S1 in a representative subject during index finger abduction (blue), precision (gray), and power grip (orange) at 30\% of MVC at an ISI of 40 ms. The amplitude of the N20/P25 component (A1 and A2, see Materials and Methods) is marked. Each waveform represents the average of 300 SSEPS. B, Group data show mean paired-pulse ratios (A2/A1) during index finger abduction (blue), precision (gray), and power grip (orange). Paired-pulse SSEP suppression of the N20/P25 was increased during power grip compared with index finger abduction and precision grip, suggesting that intracortical inhibition in the S1 was increased. C, Data from individual subjects are also shown. Error bars indicate $S E{ }^{*} p<0.05$, comparison between motor tasks; ${ }^{*} p<0.05$, comparison between test SSEP and conditioned SSEP at each task.
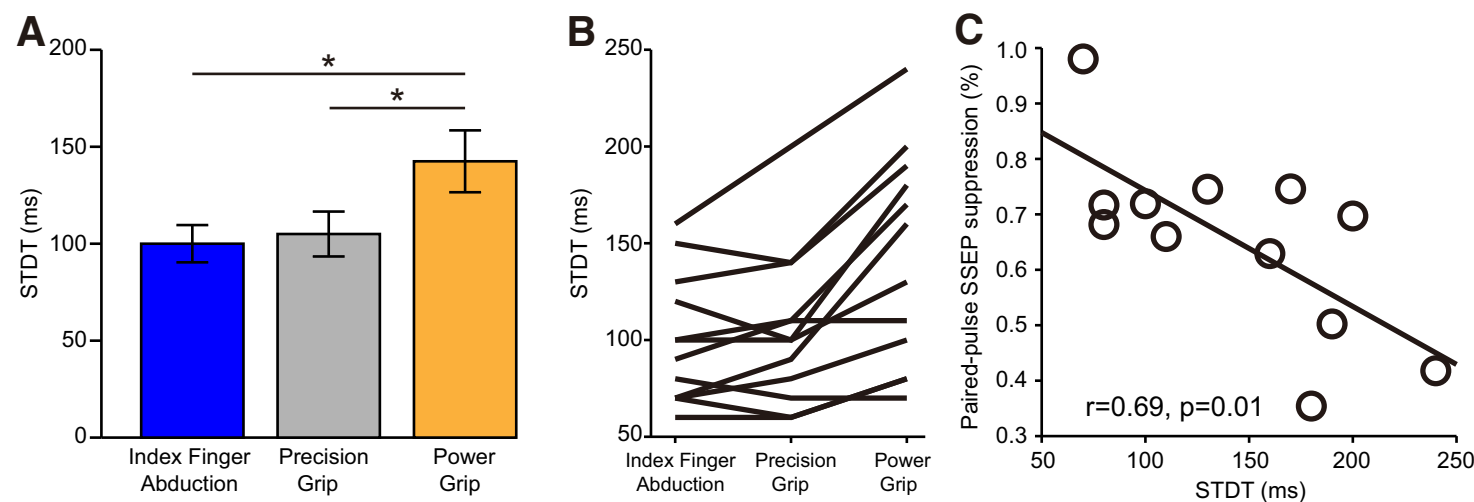

Figure 7. STDT and correlation analysis. $\boldsymbol{A}$, Group data show mean STDT values during index finger abduction (blue), precision (gray), and power grip (orange). $\boldsymbol{B}$, Data from individual subjects. C, Graphs also show a correlation between STDT and the paired-pulse suppression of the N20/P25. Individuals with higher STDT also showed a larger suppression of the N20/P25. Error bars indicate SE. ${ }^{*} p<0.05$, comparison between motor tasks.

other tasks. GABAergic-mediated cortical mechanisms play a role in modulating responses in the S1 during paired-pulse SSEP suppression (Höffken et al., 2010; Stude et al., 2016). Then, another possibility is that intracortical circuits within the S1 con- tributed to the pronounced sensory gating during power grip. This is supported by the reduced STDT during power grip compared with the other tasks. Electrophysiological (Conte et al., 2012) and neuroimaging (Pastor et al., 2004) studies showed that 
the $\mathrm{S} 1$ contributes to STDT, likely involving inhibitory interneurons within the S1 (Rocchi et al., 2016). This is also supported by the positive correlation that we found where participants with higher STDT showed stronger intracortical inhibition in the S1.

The $S 1$ is one of the first cortical receiving stations for proprioceptive afferents (Corkin et al., 1970; Lemon and van der Burg, 1979). Thus, cortical processing of sensory input at the S1 might have a limited contribution to the control of power grip as reflected by the pronounced gating of the N20/P25, whereas gating of the N20/P25 was less pronounced during precision grip and more individuated finger voluntary contractions compared with power grip. This is consistent with evidence showing that somatosensory input is important to accomplish more skilled compared with less skilled behaviors (Gentilucci et al., 1994). It is also possible that the number of fingers active during the task contributed to our results. Evidence showed that the $\mathrm{S} 1$ is more active during three- and five-digit than two-digit grasps, possibly because of the recruitment of the somatotopic zones associated with these additional digits (Cavina-Pratesi et al., 2018). Our control experiments showed that gating of the N20/P25 was similar during a precision grip using two and five fingers, suggesting that it is less likely that this factor contributed to our results. This is consistent with evidence showing that the S1 can reflect differential activation during a precision grip and more gross coarse grasping regarding of the number of fingers active (Fabbri et al., 2016). Different fingers transmit different sensory information to the S1 (Overduin and Servos, 2004; van Westen et al., 2004; Choi et al., 2015). Because we found no differences in the magnitude of sensory gating during a precision grip completed between the thumb and index finger as well as the thumb and any of the other fingers, it is less likely that this factor affected our results. This is also consistent with evidence showing that the N20/P25 is suppressed during finger movements compared with rest independent of which finger was active (Turner et al., 2002).

We also found that the amplitude of the P25/N33 decreased during all tasks compared with rest, but not in a task-dependent manner as for the other SSEP components. This is consistent with evidence showing that the P25/N33 is less affected by task context (Palmer et al., 2016; Lei and Perez, 2017). The N20/P25 can reflect activation of area 3b (Allison et al., 1991; Forss et al., 1994; Huttunen et al., 2006) and the P25/N33 of area 1 (Jones et al., 1978; Allison et al., 1991; Ishikawa et al., 2007). Although somatosensory cortical areas $3 \mathrm{~b}$ and 1 represent the initial stages for tactile information processing, these areas also exhibit distinct structural and functional organizational features (Iwamura, 1998). Area 3b has small receptive fields confined to single-digit tips, whereas the fields of area 1 neurons are typically larger and span more than one digit (Ashaber et al., 2014). A possibility would be that the $\mathrm{P} 25 / \mathrm{N} 33$ is not largely gated during power grip and other tasks because sensory information from all fingers is needed to be sent to another part of the brain for use or further processing. This agrees with results showing that larger receptive fields of area 1 could be responsible for greater digit integration and complexity on sensory processing (Iwamura et al., 1983, 1993; Sinclair and Burton, 1991; Sripati et al., 2006; Bensmaia et al., 2008; Pei et al., 2010). It is also important to consider that the amplitude of the N20/P25 and P25/N33 could be affected by a spillover effect from a previous component. However, we observed similar results when the amplitude of the N20/P25 and P25/N33 was measured from baseline to the P25 and N33 peak, suggesting that it is less likely that this factor affected our results.

\section{Functional considerations}

A main function of the hand in power grip is to provide a means of resisting forces that may be applied to the object (Napier, 1956). Lesser afferent input might well reflect the increased resisting forces required during power grip. This agrees with previous data (Sugawara et al., 2016) and with our results showing that sensory gating increases with increased level of force generation during power grip. However, during power grip, sensory gating is larger than during the other tasks, even at higher levels of force generation, suggesting that the increased sensory gating might also serve other purposes. A possibility is that lesser afferent input during gross grasping contributes to decreased neural noise in the system to better respond to external loads applied to the hand (Kirimoto et al., 2014) and unexpected motor events (Bernier et al., 2009). This agrees with results showing advantages in motor performance when the proprioceptive input is low (Jones et al., 2001; Balslev et al., 2004) or absent (Lajoie et al., 1992; Guedon et al., 1998). Pronounced sensory gating during power grip and increased inhibition in the $\mathrm{S} 1$ might also reflect the engagement of different cortical neuronal networks according to the nature of the grasping task (Tazoe and Perez, 2017). Evidence showed that distinct sets of cortical circuits and cortical areas could be engaged when humans perform a power grip compared with a precision grip (Groppa et al., 2012; Volz et al., 2015; Federico and Perez, 2017).

On the other side, patients with motor disorders showed abnormal processing of sensory signals (Bradley et al., 2009; Scontrini et al., 2009; Conte et al., 2010, 2014; Kimmich et al., 2014). For example, in patients with Parkinson's disease, increases in STDT have been associated with impaired finger dexterity (Lee et al., 2010), suggesting that the ability to process temporal sensory inputs contributes to motor tasks requiring fine fractionated finger movements. In agreement, we found that STDT values were lower during precision grip compared with power grip. Our results suggest that sensory thresholds in patients need to be considered in a task-dependent manner. Although noninvasive stimulation has been used to change discrimination thresholds in the S1 (Conte et al., 2012, 2016; Rocchi et al., 2016), we show here that discrimination thresholds can be also manipulated by simply modifying the grasping behavior.

\section{References}

Allison T, McCarthy G, Wood CC, Jones SJ (1991) Potentials evoked in human and monkey cerebral cortex by stimulation of the median nerve: a review of scalp and intracranial recordings. Brain 114:2465-2503. CrossRef Medline

Ashaber M, Pálfi E, Friedman RM, Palmer C, Jákli B, Chen LM, Kántor O, Roe AW, Négyessy L (2014) Connectivity of somatosensory cortical area 1 forms an anatomical substrate for the emergence of multifinger receptive fields and complex feature selectivity in the squirrel monkey (Saimiri sciureus). J Comp Neurol 522:1769-1785. CrossRef Medline

Baker SN, Perez MA (2017) Reticulospinal contributions to gross hand function after human spinal cord injury. J Neurosci 37:9778-9784. CrossRef Medline

Balslev D, Christensen LO, Lee JH, Law I, Paulson OB, Miall RC (2004) Enhanced accuracy in novel mirror drawing after repetitive transcranial magnetic stimulation-induced proprioceptive deafferentation. J Neurosci 24:9698-9702. CrossRef Medline

Begliomini C, Caria A, Grodd W, Castiello U (2007) Comparing natural and constrained movements: new insights into the visuomotor control of grasping. PLoS One 2:e1108. CrossRef Medline

Bensmaia SJ, Denchev PV, Dammann JF 3rd, Craig JC, Hsiao SS (2008) The representation of stimulus orientation in the early stages of somatosensory processing. J Neurosci 28:776-786. CrossRef Medline

Bernier PM, Burle B, Vidal F, Hasbroucq T, Blouin J (2009) Direct evidence 
for cortical suppression of somatosensory afferents during visuomotor adaptation. Cereb Cortex 19:2106-2113. CrossRef Medline

Blennerhassett JM, Matyas TA, Carey LM (2007) Impaired discrimination of surface friction contributes to pinch grip deficit after stroke. Neurorehabil Neural Repair 21:263-272. CrossRef Medline

Borich MR, Brodie SM, Gray WA, Ionta S, Boyd LA (2015) Understanding the role of the primary somatosensory cortex: opportunities for rehabilitation. Neuropsychologia 79:246-255. CrossRef Medline

Bradley D, Whelan R, Walsh R, Reilly RB, Hutchinson S, Molloy F, Hutchinson M (2009) Temporal discrimination threshold: VBM evidence for an endophenotype in adult onset primary torsion dystonia. Brain 132:23272335. CrossRef Medline

Brochier T, Boudreau MJ, Paré M, Smith AM (1999) The effects of muscimol inactivation of small regions of motor and somatosensory cortex on independent finger movements and force control in the precision grip. Exp Brain Res 128:31-40. CrossRef Medline

Bunday KL, Tazoe T, Rothwell JC, Perez MA (2014) Subcortical control of precision grip after human spinal cord injury. J Neurosci 34:7341-7350. CrossRef Medline

Cavina-Pratesi C, Connolly JD, Monaco S, Figley TD, Milner AD, Schenk T, Culham JC (2018) Human neuroimaging reveals the subcomponents of grasping, reaching and pointing actions. Cortex 98:128-148. CrossRef Medline

Chapman CE, Jiang W, Lamarre Y (1988) Modulation of lemniscal input during conditioned arm movements in the monkey. Exp Brain Res 72: 316-334. Medline

Choi MH, Kim HS, Baek JH, Lee JC, Park SJ, Jeong UH, Gim SY, Kim SP, Lim DW, Chung SC (2015) Differences in activation area within Brodmann area 2 caused by pressure stimuli on fingers and joints: in case of male subjects. Medicine 94:e1657. CrossRef Medline

Cohen LG, Starr A (1987) Localization, timing and specificity of gating of somatosensory evoked potentials during active movement in man. Brain 11:451-467. Medline

Conte A, Modugno N, Lena F, Dispenza S, Gandolfi B, Iezzi E, Fabbrini G, Berardelli A (2010) Subthalamic nucleus stimulation and somatosensory temporal discrimination in Parkinson's disease. Brain 133:26562663. CrossRef Medline

Conte A, Rocchi L, Nardella A, Dispenza S, Scontrini A, Khan N, Berardelli A (2012) Theta-burst stimulation-induced plasticity over primary somatosensory cortex changes somatosensory temporal discrimination in healthy humans. PLoS One 7:e32979. CrossRef Medline

Conte A, Rocchi L, Ferrazzano G, Leodori G, Bologna M, Li Voti P, Nardella A, Berardelli A (2014) Primary somatosensory cortical plasticity and tactile temporal discrimination in focal hand dystonia. Clin Neurophysiol 125:537-543. CrossRef Medline

Conte A, Belvisi D, Manzo N, Bologna M, Barone F, Tartaglia M, Upadhyay $\mathrm{N}$, Berardelli A (2016) Understanding the link between somatosensory temporal discrimination and movement execution in healthy subjects. Physiol Rep 4:e12899. CrossRef Medline

Corkin S, Milner B, Rasmussen T (1970) Somatosensory thresholds: contrasting effects of postcentral-gyrus and posterior parietal-lobe excisions. Arch Neurol 23:41-58. CrossRef Medline

Coulter JD, Maunz RA, Willis WD (1974) Effects of stimulation of sensorimotor cortex on primate spinothalamic neurons. Brain Res 65:351-356. CrossRef Medline

Datta AK, Harrison LM, Stephens JA (1989) Task-dependent changes in the size of response to magnetic brain stimulation in human first dorsal interosseous muscle. J Physiol 418:13-23. CrossRef Medline

Dawson GD (1958) The central control of sensory inflow. Proc R Soc Med 51:531-535. Medline

Dean LR, Baker SN (2017) Fractionation of muscle activity in rapid responses to startling cues. J Neurophysiol 117:1713-1719. CrossRef Medline

Desmedt JE, Cheron G (1981) Non-cephalic reference recording of early somatosensory potentials to finger stimulation in adult or aging normal man: differentiation of widespread N18 and contralateral N20 from the prerolandic P22 and N30 components. Electroencephalogr Clin Neurophysiol 52:553-570. CrossRef Medline

Ehrsson HH, Fagergren A, Jonsson T, Westling G, Johansson RS, Forssberg H (2000) Cortical activity in precision-versus power-grip tasks: an fMRI study. J Neurophysiol 83:528-536. CrossRef Medline

Enders LR, Seo NJ (2017) Effects of sensory deficit on phalanx force devia- tion during power grip post stroke. J Mot Behav 49:55-66. CrossRef Medline

Fabbri S, Stubbs KM, Cusack R, Culham JC (2016) Disentangling representations of object and grasp properties in the human brain. J Neurosci 36:7648-7662. CrossRef Medline

Federico P, Perez MA (2017) Distinct corticocortical contributions to human precision and power grip. Cereb Cortex 27:5070-5082. CrossRef Medline

Forss N, Hari R, Salmelin R, Ahonen A, Hämäläinen M, Kajola M, Knuutila J, Simola J (1994) Activation of the human posterior parietal cortex by median nerve stimulation. Exp Brain Res 99:309-315. Medline

Gentilucci M, Toni I, Chieffi S, Pavesi G (1994) The role of proprioception in the control of prehension movements: a kinematic study in a peripherally deafferented patient and in normal subjects. Exp Brain Res 99:483500. Medline

Ghez C, Pisa M (1972) Inhibition of afferent transmission in cuneate nucleus during voluntary movement in the cat. Brain Res 40:145-155. CrossRef Medline

Groppa S, Werner-Petroll N, Münchau A, Deuschl G, Ruschworth MF, Siebner HR (2012) A novel dual-site transcranial magnetic stimulation paradigm to probe fast facilitatory inputs from ipsilateral dorsal premotor cortex to primary motor cortex. Neuroimage 62:500-509. CrossRef Medline

Guedon O, Gauthier G, Cole J, Vercher JL, Blouin J (1998) Adaptation in visuomanual tracking depends on intact proprioception. J Mot Behav 30:234-248. CrossRef Medline

Hantman AW, Jessell TM (2010) Clarke's column neurons as the focus of a corticospinal corollary circuit. Nat Neurosci 13:1233-1239. CrossRef Medline

Hashimoto I, Mashiko T, Imada T (1996) Somatic evoked high-frequency magnetic oscillations reflect activity of inhibitory interneurons in the human somatosensory cortex. Electroencephalogr Clin Neurophysiol 100: 189-203. CrossRef Medline

Hikosaka O, Tanaka M, Sakamoto M, Iwamura Y (1985) Deficits in manipulative behaviors induced by local injections of muscimol in the first somatosensory cortex of the conscious monkey. Brain Res 325:375-380. CrossRef Medline

Höffken O, Lenz M, Tegenthoff M, Schwenkreis P (2010) Multichannel SEP-recording after paired median nerve stimulation suggests origin of paired-pulse inhibition rostral of the brainstem. Neurosci Lett 468:308311. CrossRef Medline

Höffken O, Tannwitz J, Lenz M, Sczesny-Kaiser M, Tegenthoff $M$, Schwenkreis P (2013) Influence of parameter settings on paired-pulsesuppression in somatosensory evoked potentials: a systematic analysis. Clin Neurophysiol 124:574-580. CrossRef Medline

Huttunen J, Komssi S, Lauronen L (2006) Spatial dynamics of population activities at $\mathrm{S} 1$ after median and ulnar nerve stimulation revisited: an MEG study. Neuroimage 32:1024-1031. CrossRef Medline

Ishikawa S, Matsunaga K, Nakanishi R, Kawahira K, Murayama N, Tsuji S, Huang YZ, Rothwell JC (2007) Effect of theta burst stimulation over the human sensorimotor cortex on motor and somatosensory evoked potentials. Clin Neurophysiol 118:1033-1043. CrossRef Medline

Iwamura Y (1998) Hierarchical somatosensory processing. Curr Opin Neurobiol 8:522-528. CrossRef Medline

Iwamura Y, Tanaka M, Sakamoto M, Hikosaka O (1983) Functional subdivisions representing different finger regions in area 3 of the first somatosensory cortex of the conscious monkey. Exp Brain Res 51:315-326.

Iwamura Y, Tanaka M, Sakamoto M, Hikosaka O (1993) Rostrocaudal gradients in the neuronal receptive field complexity in the finger region of the alert monkey's postcentral gyrus. Exp Brain Res 92:360-368. Medline

Jenner JR, Stephens JA (1982) Cutaneous reflex responses and their central nervous pathways studied in man. J Physiol 333:405-419. CrossRef Medline

Johansson RS, Flanagan JR (2009) Coding and use of tactile signals from the fingertips in object manipulation tasks. Nat Rev Neurosci 10:345-359. CrossRef Medline

Jones EG, Coulter JD, Hendry SH (1978) Intracortical connectivity of architectonic fields in the somatic sensory, motor and parietal cortex of monkeys. J Comp Neurol 181:291-347. CrossRef Medline

Jones KE, Wessberg J, Vallbo $\AA$ (2001) Proprioceptive feedback is reduced during adaptation to a visuomotor transformation: preliminary findings. Neuroreport 12:4029-4033. CrossRef Medline 
Kaas JH (1993) The functional organization of somatosensory cortex in primates. Ann Anat 175:509-518. CrossRef Medline

Kimmich O, Molloy A, Whelan R, Williams L, Bradley D, Balsters J, Molloy F, Lynch T, Healy DG, Walsh C, O'Riordan S, Reilly RB, Hutchinson M (2014) Temporal discrimination, a cervical dystonia endophenotype: penetrance and functional correlates. Mov Disord 29:804-811. CrossRef Medline

Kirimoto H, Tamaki H, Suzuki M, Matsumoto T, Sugawara K, Kojima S, Onishi H (2014) Sensorimotor modulation differs with load type during constant finger force or position. PLoS One 9:e108058. CrossRef Medline

Lajoie Y, Paillard J, Teasdale N, Bard C, Fleury M, Forget R, Lamarre Y (1992) Mirror drawing in a deafferented patient and normal subjects: visuoproprioceptive conflict. Neurology 42:1104-1106. CrossRef Medline

Lee EK, Seyal M (1998) Generators of short latency human somatosensoryevoked potentials recorded over the spine and scalp. J Clin Neurophysiol 15:227-234. CrossRef Medline

Lee MS, Lyoo CH, Lee MJ, Sim J, Cho H, Choi YH (2010) Impaired finger dexterity in patients with Parkinson's disease correlates with discriminative cutaneous sensory dysfunction. Mov Disord 25:2531-2535. CrossRef Medline

Lei Y, Perez MA (2017) Cortical contributions to sensory gating in the ipsilateral somatosensory cortex during voluntary activity. J Physiol 595: 6203-6217. CrossRef Medline

Leiras R, Velo P, Martín-Cora F, Canedo A (2010) Processing afferent proprioceptive information at the main cuneate nucleus of anaesthetized cats. J Neurosci 30:15383-15399. CrossRef Medline

Lemon RN, van der Burg J (1979) Short-latency peripheral inputs to thalamic neurones projecting to the motor cortex in the monkey. Exp Brain Res 36:445-462. CrossRef Medline

Napier JR (1956) The prehensile movements of the human hand. J Bone Joint Surg Br 38:902-913. Medline

Overduin SA, Servos P (2004) Distributed digit somatotopy in primary somatosensory cortex. Neuroimage 23:462-472. CrossRef Medline

Palmer CE, Davare M, Kilner JM (2016) Physiological and perceptual sensory attenuation have different underlying neurophysiological correlates. J Neurosci 36:10803-10812. CrossRef Medline

Paré D, Smith Y, Parent A, Steriade M (1988) Projections of brainstem core cholinergic and non-cholinergic neurons of cat to intralaminar and reticular thalamic nuclei. Neuroscience 25:69-86. CrossRef Medline

Pastor MA, Day BL, Macaluso E, Friston KJ, Frackowiak RS (2004) The functional neuroanatomy of temporal discrimination. J Neurosci 24: 2585-2591. CrossRef Medline

Pei YC, Hsiao SS, Craig JC, Bensmaia SJ (2010) Shape invariant coding of motion direction in somatosensory cortex. PLoS Biol 8:e1000305. CrossRef Medline

Perez MA, Rothwell JC (2015) Distinct influence of hand posture on cortical activity during human grasping. J Neurosci 35:4882-4889. CrossRef Medline

Ragert P, Nierhaus T, Cohen LG, Villringer A (2011) Interhemispheric interactions between the human primary somatosensory cortices. PLoS One 6:e16150. CrossRef Medline

Riddle CN, Edgley SA, Baker SN (2009) Direct and indirect connections with upper limb motoneurons from the primate reticulospinal tract. J Neurosci 29:4993-4999. CrossRef Medline

Rocchi L, Casula E, Tocco P, Berardelli A, Rothwell J (2016) Somatosensory temporal discrimination threshold involves inhibitory mechanisms in the primary somatosensory area. J Neurosci 36:325-335. CrossRef Medline

Rothwell JC, Traub MM, Day BL, Obeso JA, Thomas PK, Marsden CD (1982) Manual motor performance in a deafferented man. Brain 105: 515-542. CrossRef Medline

Scontrini A, Conte A, Defazio G, Fiorio M, Fabbrini G, Suppa A, Tinazzi M, Berardelli A (2009) Somatosensory temporal discrimination in patients with primary focal dystonia. J Neurol Neurosurg Psychiatry 80:13151319. CrossRef Medline

Seki K, Fetz EE (2012) Gating of sensory input at spinal and cortical levels during preparation and execution of voluntary movement. J Neurosci 32:890-902. CrossRef Medline

Sinclair RJ, Burton H (1991) Neuronal activity in the primary somatosensory cortex in monkeys (Macaca mulatta) during active touch of textured surface gratings: responses to groove width, applied force, and velocity of motion. J Neurophysiol 66:153-169. CrossRef Medline

Sripati AP, Yoshioka T, Denchev P, Hsiao SS, Johnson KO (2006) Spatiotemporal receptive fields of peripheral afferents and cortical area $3 \mathrm{~b}$ and 1 neurons in the primate somatosensory system. J Neurosci 26:2101-2114. CrossRef Medline

Starr A, Cohen LG (1985) "Gating" of somatosensory evoked potentials begins before the onset of voluntary movement in man. Brain Res 348:183186. CrossRef Medline

Steriade M, Paré D, Parent A, Smith Y (1988) Projections of cholinergic and non-cholinergic neurons of the brainstem core to relay and associational thalamic nuclei in the cat and macaque monkey. Neuroscience 25:47-67. CrossRef Medline

Stude P, Lenz M, Höffken O, Tegenthoff M, Dinse H (2016) A single dose of lorazepam reduces paired-pulse suppression of median nerve evoked somatosensory evoked potentials. Eur J Neurosci 43:1156-1160. CrossRef Medline

Sugawara K, Onishi H, Yamashiro K, Kotan S, Kojima S, Miyaguchi S, Tsubaki A, Kirimoto H, Tamaki H, Shirozu H, Kameyama S (2016) Effect of muscle contraction strength on gating of somatosensory magnetic fields. Exp Brain Res 234:3389-3398. CrossRef Medline

Tazoe T, Perez MA (2017) Cortical and reticular contributions to human precision and power grip. J Physiol 595:2715-2730. CrossRef Medline

Tsumoto T, Nakamura S, Iwama K (1975) Pyramidal tract control over cutaneous and kinesthetic sensory transmission in the cat thalamus. Exp Brain Res 22:281-294. Medline

Turner LC, Harrison LM, Stephens JA (2002) Finger movement is associated with attenuated cutaneous reflexes recorded from human first dorsal interosseous muscle. J Physiol 542:559-566. CrossRef Medline

van Westen D, Fransson P, Olsrud J, Rosén B, Lundborg G, Larsson EM (2004) Fingersomatotopy in area 3b: an fMRI study. BMC Neurosci 5:28. CrossRef Medline

Volz LJ, Hamada M, Rothwell JC, Grefkes C (2015) What makes the muscle twitch: motor system connectivity and TMS-induced activity. Cereb Cortex 25:2346-2353. CrossRef Medline 